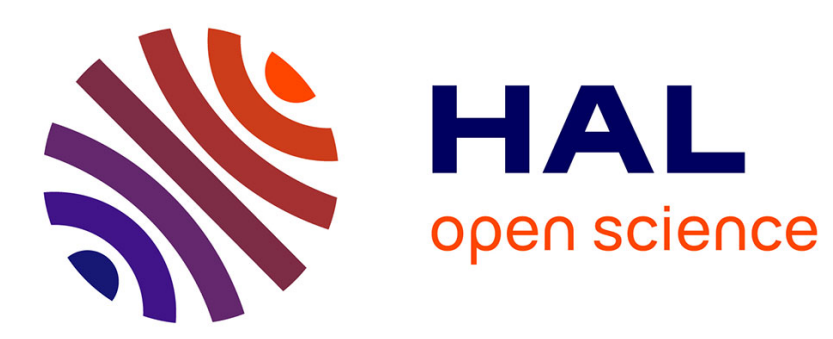

\title{
Causal Attributions of Workplace Gender Equality, Just World Belief, and the Self/Other Distinction
}

\author{
Marina Bastounis, Jale Minibas-Poussard
}

\section{To cite this version:}

Marina Bastounis, Jale Minibas-Poussard. Causal Attributions of Workplace Gender Equality, Just World Belief, and the Self/Other Distinction. Social behavior and personality, 2012, 40 (3), pp.433 452. 10.2224/sbp.2012.40.3.433 . hal-01615540

\author{
HAL Id: hal-01615540 \\ https://hal.science/hal-01615540
}

Submitted on 18 Oct 2018

HAL is a multi-disciplinary open access archive for the deposit and dissemination of scientific research documents, whether they are published or not. The documents may come from teaching and research institutions in France or abroad, or from public or private research centers.
L'archive ouverte pluridisciplinaire HAL, est destinée au dépôt et à la diffusion de documents scientifiques de niveau recherche, publiés ou non, émanant des établissements d'enseignement et de recherche français ou étrangers, des laboratoires publics ou privés. 


\title{
CAUSAL ATTRIBUTIONS OF WORKPLACE GENDER EQUALITY, JUST WORLD BELIEF, AND THE SELF/OTHER DISTINCTION
}

\author{
MARINA BASTOUNIS \\ Paris Descartes University \\ Jale Minibas-Poussard \\ Galatasaray University
}

\begin{abstract}
We conducted 2 surveys in Istanbul, Turkey, to investigate the moderating effects of belief in a just world (BJW) on the links between perceived gender equality and causal attributions in the workplace with 2 samples of bank employees from varying hierarchical positions $(M$ age $=$ 30). Results from a unidimensional BJW scale (Dalbert \& Yamauchi, 1994) used in Study 1 ( $N$ = 136) showed a negative relationship between perceived gender equality and internal causal attributions only for high BJW scores. Results from a bidimensional scale measuring BJW for self and for others (Lipkus, Dalbert, \& Siegler, 1996) used in Study $2(N=168)$ replicated this pattern for BJW both for self and for others. However, only BJW for others, which was found to be linked to social discrimination indices, moderated the negative relationship between perceived gender equality and external attributions. These findings support the relevance of the bidimensional conception of BJW and the predictions related to causal attribution theory and the just world hypothesis.
\end{abstract}

Keywords: belief in a just world, causal attribution, workplace gender equality, self/other distinction.

Belief in a just world (BJW) is often examined in terms of a fundamental attitudinal orientation involving individuals buffering negative feelings when

Marina Bastounis, Institute of Psychology, Paris Descartes University; Jale Minibas-Poussard, Business Administration Department, Galatasaray University.

This research was funded by the Galatasaray University Scientific Research Committee in Istanbul, Turkey. The authors wish to thank the University of Galatasaray for supporting all stages of this project. The authors are listed in alphabetical order.

Please address correspondence and reprint requests to: Marina Bastounis, Paris Descartes University, 71 Avenue Edouard Vaillant, 92744 Boulogne-Billancourt, France. Email: marina.bastounis@ parisdescartes.fr 
faced with injustice and victimization (see Montada, 1998). Originally defined as the fundamental need to believe that in this world people get what they deserve (Lerner, 1965, 1980; Lerner \& Miller, 1978) BJW was soon shown to function as a cognitive bias activated to justify observed injustice. For example, in one of the early experimental investigations, Zuckerman (1975) showed that one way for individuals to maintain their BJW was for them to engage in action that helped the victims of injustice. When action, or the selected option, is not an available, another cognitive strategy that can be employed to sustain BJW is to minimize the social inequalities that pose a challenge to it.

On a collective scale, it has been demonstrated in cross-cultural comparisons that there is another important role played by BJW: since the belief acts to justify observed social injustice, it buffers the effects of perceived inequality, and thereby makes life bearable in overtly unjust situations and societies. An example of this buffering in operation is provided in Furnham's (1985) study in South Africa before the abolition of apartheid. He concluded that BJW functioned to help people make sense of the status quo and cope with it. In Western societies BJW has been shown to be positively related to political conservatism and the endorsement of traditional roles for women (Furnham \& Karani, 1985; Wagstaff \& Quirk, 1983). BJW seems, then, to motivate the denial of injustice through changing one's views about the facts, instead of trying to change the facts themselves.

In turn, however, strong BJW seems to come with several psychological benefits. Dalbert (1998) showed that on a personal level BJW helps people who are themselves victims of an unjust fate to cope with their predicament. Later, the same author argued that this happens because BJW decreases feelings of anger in people who experience negative events. Through this mechanism, BJW can sustain feelings of well-being (Dalbert, 2002). A rich literature links BJW with a number of measures of psychological adjustment including mental health in unemployed adolescents (Dzuka \& Dalbert, 2002), homeless people's optimism (Littrell \& Beck, 1999), elderly people's quality of sleep (Jensen, Dehlin, Hagberg, Samuelsson, \& Svensson, 1998), general lower levels of depression (Ritter, Benson, \& Snyder, 1990), more effective coping with potential stress (Tomaka \& Blascovich, 1994) and stronger positive affect (Dalbert, 1998).

Such psychological benefits would explain why individuals activate cognitive mechanisms to secure their belief in a just world against contradictory evidence by minimizing the injustices that they see happening to others. Alternative strategies through which apparent injustice may be minimized include blame and victim derogation (Lerner \& Miller, 1978; and for a review of experimental studies see Hafer \& Bègue, 2005). BJW is involved with the evaluation of social targets in that negative attitudes toward sufferers of unjust conditions may be activated. BJW scores have been found to correlate with negative attitudes toward poor 
people (Furnham \& Gunter, 1984; Wagstaff, 1983) and poor countries (Harper \& Manasse, 1992; Harper, Wagstaff, Newton, \& Harrison, 1990). Similarly, BJW has been linked to strongly negative attitudes toward refugees (Montada, 1998), AIDS patients (Connors \& Heaven, 1990), the unemployed (Reichle, Schneider, \& Montada, 1998), and the elderly (Lipkus \& Siegler, 1993).

Smith (1985) demonstrated that beyond the derogation of the poor and valorization of the rich, BJW was linked to internal causal attributions of both poverty and wealth. These results were corroborated by Harper et al. (1990) and Harper and Manasse (1992) who examined lay causal perceptions of third world poverty and reported strong evidence for "blame the poor" attitudes. In other words, according to the just world motive, evident injustice is minimized through a cognitive schema whereby people not only get what they deserve, but they also get that they choose. Following on from this line of research in the present study we set out to examine the role of BJW in relation to perceived gender equality in the workplace.

\section{Belief in a Just World and Gender Equality in the Workplace}

Ruggiero and Taylor (1997) focused on gender differences in how women as a minority group perceive discrimination of which they are the victims. They analyzed participants' recollections of their job performance evaluations and reported that women minimized observed bias (injustice) against their own performance, by means of buffering, self-protective thinking about justice linked to the belief in a just world. Dalbert, Fisch, and Montada (1992) investigated career opportunities for men and women in Germany and demonstrated that BJW was not only one of the most important predictors of rating equality in the professional world but also that it was correlated to denial of gender inequalities. More importantly, the authors tested the nature of arguments used by the participants in their study to explain observed inequalities in order to reduce the perceived injustice of the situation for women that could been seen objectively to be less favorable. The hypothesis was that women's less favorable career opportunities might be attributed to the nature and choices of women themselves (internal causal attribution). The results, however, showed that, rather than any internal causal attribution being involved, the effect of BJW on rated equality was mediated by denial of social discrimination against women in their professional life (external causal attributions). That is, the more these individuals believed that the world was just, the more they seemed to deny both injustice toward women, and also explanations for observable gender injustice related to social norms. The specific variables measured as external attributions in that study were "unequal treatment of women in their profession" and "loss of attractiveness of women who choose to follow a career". However, internal causal attributions for gender differences 
were, in themselves, negatively correlated with ratings of justice, and the authors called for more research to clarify the relationships between these concepts.

In 2009, Otto, Glaser, and Dalbert conducted a longitudinal study with employed and unemployed people in Germany, in which they tested the relationships between personal BJW and evaluations of working life, mental health, and occupational trust. The data revealed that the relationships between BJW and the tested variables persisted when controlling for objective success criteria as well as for global personality traits. The authors emphasized the importance of studying the operation of BJW in the workplace. According to their findings, BJW serves as a way to assimilate experienced injustices and uphold positive evaluations of the workplace, thus protecting mental health and promoting positive measures of organizational citizenship.

In this context, and in order to replicate the study conducted in Germany by Dalbert and colleagues in 1992, we set out to explore the links between BJW, perceived gender equality, and internal and external causal attributions of perceived equality. Based on the literature cited above, we assumed first that people who strongly believe that the world overall is just would also believe that men and women have equal opportunities in the workplace. In other words, we expected that BJW scores would be positively and significantly correlated with higher scores for perceived gender equality (H1).

Further, we hypothesized that people who believe that globally the world is just, would have high scores on perceived gender equality and would link their evaluation of gender equality to causes intrinsic to women themselves. According to the justice motive as it is discussed by Otto et al. (2009), BJW would, in that case, serve as a framework within which inequalities are explained, assimilated, and do not undermine evaluations of the workplace and occupational well-being. People who believe that the world is just but who also believe that men and women do not enjoy equal opportunities at work, would then uphold the belief that women themselves choose to have less favorable career opportunities and are personally responsible for achieving less than men professionally. In other words, we expected that BJW would moderate the relationship between perceived gender equality and internal causal attributions, so that only people with a high BJW score would link perceived gender equality and internal causal attributions referring to the nature and choices of women themselves $(\mathrm{H} 2)$.

\section{Belief in a Just World for the Self and for Others}

The unidimensional conceptualization of just world beliefs has been questioned (Furnham, 2003) and several suggestions of more than one distinction have been made. Maes (1998) discussed the distinction between perceptions of immanent versus ultimate justice; other authors have suggested the distinction between 
perceptions of the world as being, or not being, just versus the world being, or not being, unjust (Connors \& Heaven, 1990; Furnham, 1985). Following extensive criticism of the unidimensional belief in a just world and also of the psychometric qualities of unidimensional general BJW scales, Lipkus, Dalbert, and Siegler (1996) developed an instrument that taps two dimensions of believing that the world is just: the world is just for me (self; BJW-S) and the world is just for others (BJW-O). Lipkus et al. measured BJW-S and BJW-O with 16 items (e.g., "I feel that I get what I deserve" and "I feel that people get what they deserve") in two subscales of eight items and the instrument was shown to be highly internally consistent. It is of note that the correlation between the two subscales was surprisingly modest. Scores on the BJW-S scale were also much higher than those on the BJW-O scale (Bègue, 2002; Bègue \& Bastounis, 2003).

Underscoring this distinction, BJW-S and BJW-O have different correlates. Overall, belief in a just world for oneself was found to be linked to psychosocial adjustment and well-being, but not to social discrimination and harsh social attitudes, while belief in a just world for other people was found to be related to social discrimination indices but not to psychosocial adjustment (cf. Bègue \& Bastounis, 2003; Lipkus et al., 1996). Lipkus et al. found BJW-S, but not BJW-O, to be related to indices of well-being such as positive affect, life satisfaction, and low stress levels. Similarly, BJW-S, but not BJW-O, has been found to be related to life satisfaction (Dalbert, 1999), low scores on depression inventories (Dzuka \& Dalbert, 2002), and greater purpose in life (Bègue \& Bastounis, 2003). Conversely, BJW-O, but not BJW-S, has been found to be associated with social outcomes such as prejudice toward the elderly and the poor (Bègue \& Bastounis, 2003).

Sutton and Douglas (2005) provided further support for the distinction between perceived justice for self and for others, by testing whether or not third variables would be implicated in these patterns of relationships. These authors measured BJW-S and BJW-O, and examined their links with attitudes toward the poor (social attitude criterion variable) and life satisfaction (well-being criterion variable) while statistically controlling for the effects of locus of control, self-esteem, and socially desirable responding. They verified that BJW-S was related only to psychological adjustment measures, and BJW-O was uniquely related to harsher attitudes toward the poor. The authors emphasized that these relationships were not attributable to the influence of third key causes and suggested that just-world beliefs should not be viewed as a single construct with psychological benefits and adverse social consequences because although BJW-S and BJW-O have different relationships with other variables the two constructs are positively correlated with each other, and, therefore, they may mask each other's effects. For this reason, the distinction between evaluating justice for the self versus evaluating justice for others became central to the development of our 
study design and we decided to replicate the study by Sutton and Douglas (2005) but to replace the unidimensional scale with the bidimensional scale of BJW-S and BJW-O developed by Lipkus et al. in 1996.

Therefore, we set out first to replicate previous findings regarding the discriminant validity for the bidimensional conceptualization of BJW proposed by Lipkus et al. (1996). According to the literature we expected that both BJW-O and BJW-S would be related to beliefs in equality of people's chances to succeed in the world. People who believe that the world is just for themselves and for others would also endorse perceptions of equality between genders in the workplace; people who do not hold those beliefs would perceive inequality between men and women in terms of professional opportunities and achievements. In other words, we expected to find a positive correlation between BJW-S and BJW-O scores and scores of perceived gender equality (H3).

Similarly, we assumed that both BJW-S and BJW-O would moderate the relationship between internal causal attributions and perceived equality, with both dimensions functioning in the same way as general BJW. In other words, people who believe that the world is just for themselves and for others would link their perception of gender equality to internal attributions, that is, the nature and choices of women themselves. However, only BJW-O, which is linked to the acceptance and endorsement of social discrimination (Bègue \& Bastounis 2003; Lipkus et al., 1996; Sutton \& Douglas, 2005), and not BJW-S, would be involved in the link between external attributions and perception of gender equality. In other words, we expected that only BJW-O (and not BJW-S) scores would moderate the relationship between gender equality and external causal attributions (i.e., pertaining to social discrimination between men and women). This being so, only people who would believe that the world is just for others would link gender equality to external attributions (H4).

\section{Study 1}

Study 1 was inspired by the investigation of Dalbert et al. (1992) on the causal attributions of gender equality in the workplace and our aim in the study was to test their findings in Turkey. In Hofstede's $(1980,1991)$ examination of cultural differences in value orientations Turkey's mean masculinity index was 53 (mean for 39 countries was 51) and the country was ranked 26th among 39 countries, thus being assessed as having an average masculine value orientation. However, in recent years issues related to gender equality in professional opportunities and achievements have come to the forefront of Turkey's development objectives. For instance, the 2009 Human Development Report published by the United Nations Development Programme (2009) ranks Turkey 90th out of the 93 countries for which gender empowerment statistics, as one of the five indicators used in the report, are available for the Gender Empowerment Measure, that is, an index 
of women's and men's abilities to be active participants in their economic and political life and command their economic resources. A number of other indices further attest to gender inequality of opportunities for women in Turkey in the professional sphere, for instance, the percentage of Turkish women compared to men in paid employment as legislators, senior officials, and managers is only $9 \%$ (United Nations Development Programme, 2009).

In 2006, the government of Turkey and the United Nations Development Programme signed a Country Programme Document (CPD) of which the aim is to bring changes in the area of gender equality by 2010 . Gender disparities are detailed in the document in public, economic, and political life and these disparities are identified as constraints in achieving gender equality. The document also describes women in Turkey as a disadvantaged social group who "have been excluded from involvement in these areas of life resulting in exclusion from economic opportunities and limited political representation and empowerment" (United Nations Development Programme, 2006, p. 12). One of the objectives of the program was to increase female participation in local and national elections both as voters and candidates by 2010 .

The survey we conducted for the current study was carried out in the banking sector, which according to data provided by the Turkish Bank Association (2009) was characterized by employment parity between genders with almost $50 \%$ of all employees being female. However, in top management only $16.3 \%$ of the positions were held by females and on boards of directors a meager $2.8 \%$ of the members were female (Ararat \& Tansel-Çetin, 2009).

Therefore, our purpose in this study was to collect data from a survey carried out across the entire hierarchy of positions in the banking sector in Istanbul, Turkey. Our aim was to test two findings about general just world belief (BJW) that have been widely validated in Western societies: first, that BJW is positively linked to perceived gender equality (H1). Furthermore, inspired by the study conducted by Dalbert et al. (1992) in Germany, in this study our aim was to examine the moderating role of BJW in the relationships between perceived gender equality ratings and causal attributions of equality that are intrinsic to women $(\mathrm{H} 2)$.

\section{Method}

Sample. A survey was carried out with employees working at all levels of responsibility and seniority in the hierarchy of banks, in Istanbul, Turkey. We distributed 200 questionnaires to a number of branches and desks of the same banking institution, through private contacts with upper management.

We received 136 completed questionnaires from participants $(M$ age $=30$, range $=23-40)$ of whom about half $(51.5 \%)$ were married and $45.6 \%$ were single. The majority of the respondents $(72.1 \%)$ were female and the rest $(27.9 \%)$ 
were male. Over half of the sample (64.7\%) had university education with an additional $27.5 \%$ holding postgraduate qualifications. Twenty-four percent of the sample held higher level managerial posts, $33 \%$ were middle-level managers, and the remaining $53 \%$ were in lower level white-collar positions. Almost $50 \%$ of the sample had over 5 years experience in the banking industry.

Instrument. The instrument used to measure belief in a just world was taken from Dalbert and Yamauchi's (1994) Belief in a Just World Scale $(\alpha=.79)$ and rated on a 6-point Likert-type scale. The Turkish version of this scale was back-translated blind by a bilingual speaker to check for the reliability of the translation. In addition, three scales based on the work of Dalbert and Yamauchi (1994) were presented in order to measure perceived gender equality and internal and external causal attributions of perception of equality in the workplace:

Perceived gender equality. The belief that men and women are equal in the professional arena was measured by four items. Example item: "At work, equal trust is given to both men and women".

External causal attribution of gender equality. The belief that society on the whole is responsible for gender differences in career opportunities was measured with five items. Example item: "After a woman marries and has children her environment forces her to put her professional aspirations aside".

Internal causal attribution of perceived gender equality. The belief that women, because of their nature, voluntarily do not choose career equality with men was measured with five items. Example item: "After a certain time, women lose their passion for professional success".

The data were tested with factor analyses to establish the item loadings (above .40) and homogeneity of the three scales (perceived gender equality $\alpha=.70$; internal attributions $\alpha=.77$; and external attributions $\alpha=.77$ ).

\section{Results and Discussion}

Correlational analyses revealed that, as hypothesized (H1), BJW scores were positively correlated with perceived gender equality scores $(r=.21, p \leq .01)$. In other words, the more people believed that the world is just, the higher they rated equality between genders in the workplace (see Table 1). In addition, perceived gender equality scores were significantly negatively correlated with internal and external attributions ( $r=-.19, p \leq .05$ and $r=-.24, p \leq .001$, respectively).

Table 1. Means, Standard Deviations, and Correlation Coefficients (Study 1)

\begin{tabular}{lccccc}
\hline & $M$ & $S D$ & 1 & 2 & 3 \\
\hline BJW & 19.99 & 4.97 & & & \\
Gender equality & 12.49 & 2.79 & $-.21^{*}$ & & \\
Internal attributions & 12.80 & 4.22 & -.07 & $-.19^{*}$ & \\
External attributions & 19.10 & 4.96 & -.08 & $-.24^{* *}$ & $.45^{* *}$ \\
\hline
\end{tabular}

Notes: ${ }^{*} p \leq .05,{ }^{* *} p \leq .001$. 
In order to test whether or not there were systematic differences between male and female scores we first calculated $F$ test scores comparing results for male and female participants. These analyses did not reveal any significant differences between genders in terms of gender equality, BJW, or internal or external attribution scores. In addition, in order to eliminate other possible gender biases we also tested the interaction effect of BJW $\mathrm{x}$ gender on perceived gender equality, and this was not significant. For both genders, the higher the BJW scores, the higher the perceived gender equality scores (see Figure 1).

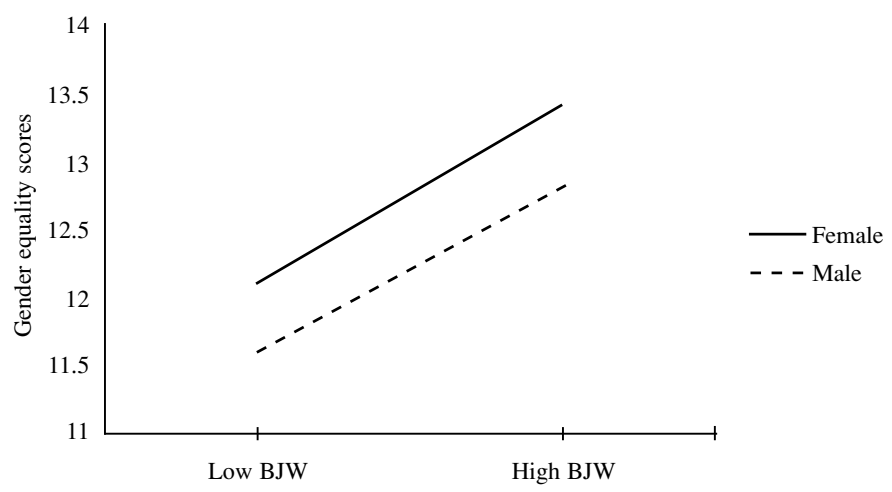

Figure 1. The relationship between BJW and perceived gender equality as a function of gender.

Following this control, we conducted a series of hierarchical regression analyses to test causal relationships between the variables under study. The results showed that internal attributions scores were predicted by gender equality $\left(R=.19, R^{2}=.03, F=5.12, \beta=.21 p \leq .05\right)$ but not by BJW $(\beta=-.02 p \leq .76)$. Based on these results, we tested the moderation effect of BJW on the relationship between perceived gender equality and internal attributions (H2). According to the method described by Aiken and West (1991), the three variables were first centered and the interaction term was calculated based on the centered scores. The BJW $x$ perceived gender equality interaction effect on internal attributions was significant when BJW was high $\left(R=.40, R^{2}=.16, F=5.95, \beta=-.40, p \leq\right.$ $.05)$ but not when BJW was low $\left(R=.07, R^{2}=.005, F=.73, \beta=-.07, p \leq .70\right)$. The BJW x perceived gender equality interaction on external attributions had no significant effects.

Simple slopes analysis was carried out to further illustrate the effect of the BJW x perceived gender equality interaction on internal attributions. When BJW was high (one $S D$ above the mean), the negative relationship between internal attributions and gender equality was significant, but when BJW scores were low (one $S D$ below the mean) it was not. In other words, only the people who believe 
the world is just globally also link low perceived gender equality to factors intrinsic to women (see Figure 2).

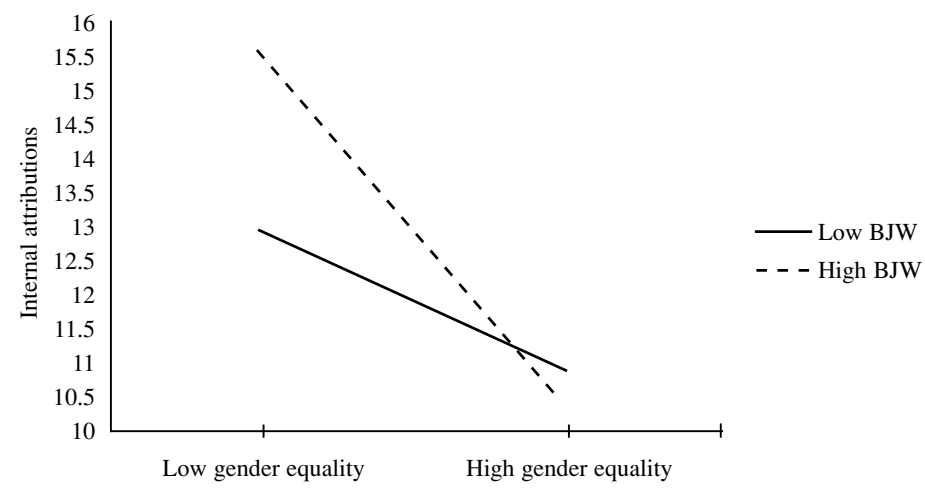

Figure 2. The relationship between perceived gender equality and internal attributions as a function of BJW.

\section{Study 2}

We carried out a survey in Istanbul to test the role of the bidimensional conceptualization of BJW in the relationship between perceived gender equality and causal attributions. In previous studies it has been suggested that there is a heuristic value in the distinction between believing that the world is just for oneself (BJW-S) and believing that the world is just for others (BJW-O). The scale developed by Lipkus et al. (1996) to test that value has shown satisfactory discriminant validity with European samples.

Similarly to our hypothesis in Study 1 we expected to find a positive correlation between BJW-S and BJW-O and gender equality scores (H3). In addition, given the literature linking, BJW-S but not BJW-O, to sociopsychological adjustment measures and BJW-O, but not BJW-S, to the endorsement of harsher social attitudes and social discrimination indices (Bègue \& Bastounis, 2003; Lipkus et al., 1996; Sutton \& Douglas, 2005) we expected that BJW-O, but not BJW-S, would moderate the link between perceived equality and external attributions (H4). In other words, we expected that only people who believe that the world is just for others would link their evaluation of gender equality to social values and norms whereby inequality between men and women in the workplace is accepted.

\section{Method}

The instrument used in Study 1 was employed again, except that instead of measuring general BJW we measured BJW-O and BJW-S with the scale developed by Lipkus et al. (1996). The sample $(N=168)$ was composed of bank 
employees $(M$ age $=30$, range $=24-42)$. Fifty-one percent were female; $59 \%$ were married and $34 \%$ single. The majority had university education $(66 \%$, and an additional $23 \%$ held a postgraduate qualification). Twenty-three percent of the sample held higher level managerial posts, $33 \%$ were middle-level managers, and $47 \%$ were lower level white-collar workers. Thirty-five percent had less than 5 years experience in the bank and $65 \%$ over 5 years experience. This sample resembled the composition of the sample used in Study 1 in terms of the main demographic variables controlled.

Gender equality and attributions scales were retested for psychometric qualities and showed satisfactory homogeneity (perceived gender equality $\alpha=$ .73 , internal attributions $\alpha=.74$, external attributions $\alpha=.72$ ). The BJW-S and BJW-O dimensions were established through factorial analysis (factor load above .40 , see Table 2) and showed satisfactory homogeneity (Cronbach's $\alpha=89$ for both scales).

Table 2. Factor Analysis for BJW-S and BJW-O Dimensions (Study 2)

\begin{tabular}{lcc}
\hline & Factor 1 & Factor 2 \\
\hline 1. I feel that I get what I am entitled to in life & .73 & .12 \\
2. I feel that my efforts are noticed and rewarded & .86 & .16 \\
3. I feel that I am treated fairly in life & .76 & .10 \\
4. I feel that I earn the rewards and punishments I get & .52 & .18 \\
6. I feel that I get what I deserve & .59 & .32 \\
7. I feel that I am treated with the respect that I deserve & .74 & .15 \\
8. I feel that the world treats me fairly & .66 & .26 \\
1. I feel that people get what they are entitled to in life & .29 & .55 \\
2. I feel that people's efforts are noticed and rewarded & .26 & .53 \\
3. I feel that people are treated fairly in life & .23 & .61 \\
4. I feel that people earn the rewards and punishments they get & .27 & .60 \\
6. I feel that people get what they deserve & .30 & .72 \\
7. I feel that people are treated with the respect that they deserve & .26 & .74 \\
8. I feel that the world treats people fairly & .25 & .80 \\
\hline
\end{tabular}

Note: Items with weight in italics were not retained for the factors.

\section{Results and Discussion}

Correlation analyses revealed results that overall replicated those of Study 1. Perceived gender equality ratings were positively correlated to both BJW-O ( $r$ $=.31, p \leq .001)$ and BJW-S $(r=.32, p \leq .001)$. In addition, perceived gender equality scores were negatively and significantly correlated with internal and external attributions ( $r=-.14$ and $r=-.20$, respectively, $p \leq .05$ ). 
Table 3. Means, Standard Deviations, and Correlation Coefficients (Study 2)

\begin{tabular}{lcccccc}
\hline & $M$ & $S D$ & 1 & 2 & 3 & \\
\hline BJW-S & 32.02 & 6.85 & & & & \\
BJW-O & 23.95 & 9.61 & $.70^{*}$ & & & \\
Gender equality & 15.98 & 3.82 & $.31^{* *}$ & $.32^{* *}$ & & \\
Internal attributions & 13.86 & 4.31 & -.11 & -.07 & $-.14^{*}$ & \\
External attributions & 19.63 & 4.18 & .05 & -.10 & $-.20^{*}$ & $.29^{* *}$ \\
\hline
\end{tabular}

Notes: ${ }^{*} p \leq .05,{ }^{* *} p \leq .001$.

As in Study 1, we controlled for systematic differences between male and female scores. $F$ test results showed no significant differences between genders in terms of BJW, perceived gender equality, or internal and external attributions scores. Following the same procedure that we used in Study 1, we tested the interaction effect of participant gender $\mathrm{x}$ BJW on gender equality, in order to further control for gender bias. The interaction of BJW-S and BJW-O scores and gender with perceived gender equality was not significant. For both genders, the higher were the BJW scores for both self and others, the higher were perceived gender equality scores.

We then tested for causal relationships between the variables under study. Hierarchical regression analyses indicated that internal attributions were predicted by gender equality $\left(R=.17, R^{2}=.02, F=3.51 ; \beta=-.16, p \leq .05\right)$ but not BJW-S and BJW-O ( $\beta=-.09, p \leq .15 ; \beta=-.05, p \leq .72$, respectively). Based on these results we conducted moderation analyses to test the effect of BJW-S and BJW-O on the relationship between perceived gender equality and internal attributions. The analyses indicated that the relationship between perceived gender equality and internal attributions was, in fact, moderated by BJW-S. The relationship between perceived gender equality and internal attributions was significant only when BJW-S was high (one $S D$ above the mean, $R=.34, R^{2}=.11, F=10.49$; $\beta=-.34, p \leq .01$ ) but not when it was low (one $S D$ below the mean, $R=.02$, $R^{2}=.001, F=.06, \beta=-.02, p \leq .42$; see slopes analyses in Figure 5). These results indicate that people who believed the world is just for themselves linked low perceived gender equality to causes intrinsic to women, that is to say, these people made internal causal attributions.

This relationship was also moderated by BJW-O scores. When BJW-O scores were high, the relationship between perceived gender equality and internal attributions was significant $\left(R=.27, R^{2}=.07, F=5.71, \beta=-.27, p \leq .01\right)$ but this relationship was not significant when BJW-O scores were low $\left(R=.11, R^{2}\right.$ $=.02, F=1.4 ; \beta=-.11, p \leq .30$ ). These results indicate that only people who believed the world is just for others linked low perceived gender equality to causes intrinsic to women (see slopes analyses in Figure 6). 


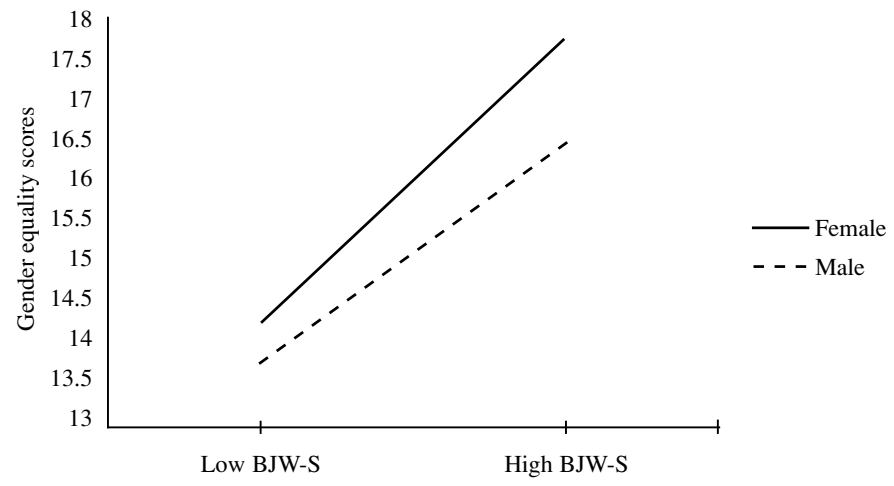

Figure 3. The relationship between BJW-S and perceived gender equality as a function of gender.

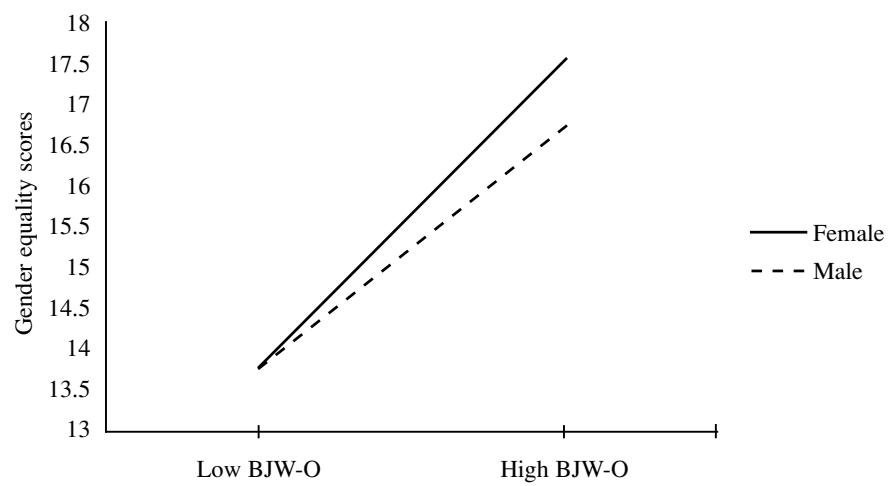

Figure 4. The relationship between BJW-O and perceived gender equality as a function of gender.

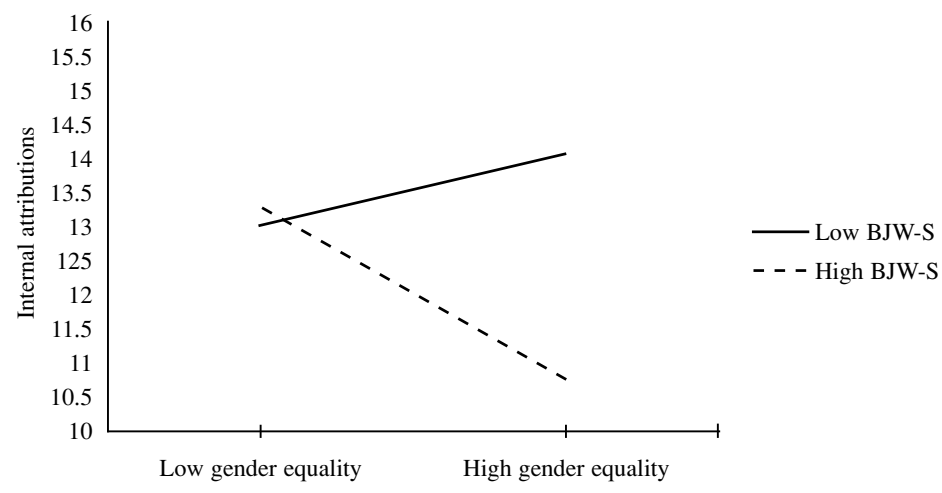

Figure 5. The relationship between perceived gender equality and internal attributions as a function of BJW-S. 
Hierarchical regression analyses showed that perceived external attributions were predicted by gender equality $\left(R=.33, R^{2}=.10, F=9.88, \beta=-.27, p \leq\right.$ $.01)$ but not by either BJW-S or BJW-O ( $\beta=-.08, p \leq .14 ; \beta=-.10, p \leq .09$, respectively). Based on these results we conducted a moderation analysis to test the effect of BJW-O and BJW-S on the relationship between perceived gender equality and internal attributions. The results indicated that this negative relationship was significant only when BJW-O was high (one $S D$ above the mean, $R=.26, R^{2}=.07, F=6.22, \beta=-.26, p \leq .01$ ) and was not significant when BJW-O was low (one $S D$ below the mean, $R=.01, R^{2}=.0001, F=0.22$, $\beta=-.01, p \leq .88$ ). In other words, only people who believe that the world is just for others linked low perceived gender equality with causes that were not

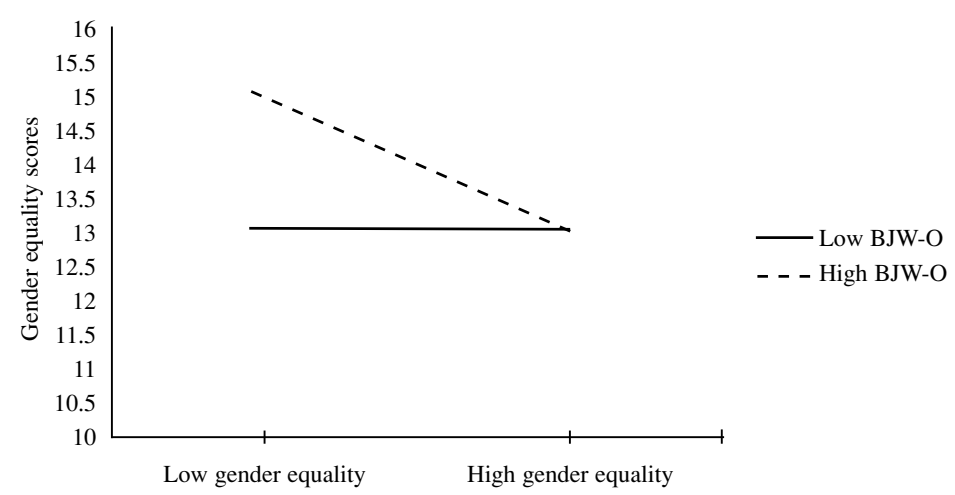

Figure 6. The relationship between perceived gender equality and internal attributions as a function of BJW-O.

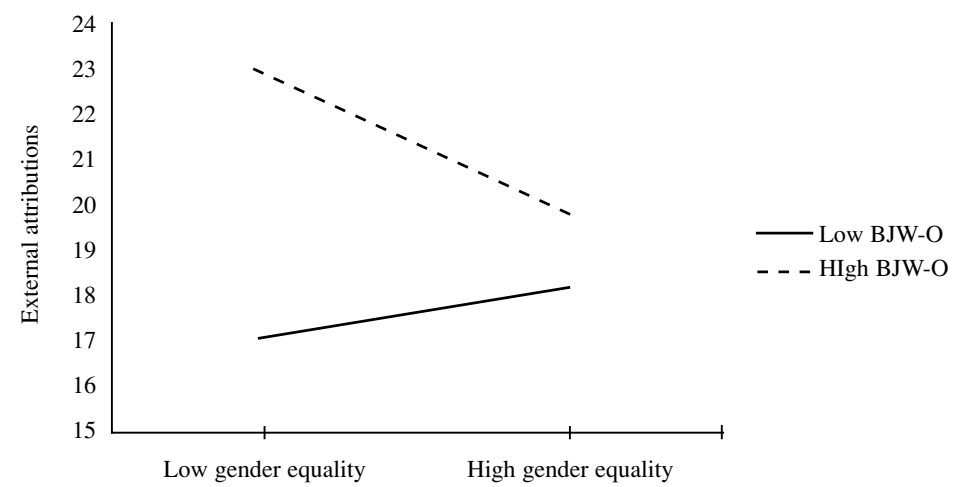

Figure 7. The relationship between perceived gender equality and external attributions as a function of BJW-O. 
intrinsic to women, that is to say these people made external attributions $(\mathrm{H} 4$, see slopes analyses in Figure 7).

The relationship between external attributions and perceived gender equality was not moderated by BJW-S scores.

\section{General Discussion}

In these two studies we examined just world belief correlates in terms of gender equality in the workplace and their causal attributions. Our findings largely support those of related literature regarding the role of BJW as a general attitudinal orientation linked to the minimization of social inequalities that appears to have a psychosocial adaptive function. The data from our first study tend to verify the relationship between believing that the world is just and perceiving gender equality in the workplace, despite being conducted in a context that was marked in the years between 2005 and 2010 by public debate in Turkey on pervasive gender inequalities in terms of professional opportunities. In addition, the present results hold for both males and females. We controlled for the effects of gender a posteriori, but did not observe any significant differences between men and women on any of the measured variables. Higher just world beliefs are, therefore, linked to denial of low gender equality by both genders.

These results confirm those of a long tradition of literature on the justice motive theory, wherein the denial of existing inequalities is interpreted as a buffer to the possible stress generated by perceived low gender equality. Otto et al. (2009) demonstrated strong positive links between BJW, mental health, and occupational trust, when they controlled for objective success criteria and global personality traits. Theirs was one of the few rare longitudinal studies in which the positive consequences of believing the world is just were explored, and the findings clearly demonstrate that personal BJW helps people across different career situations to maintain mental health (e.g., life satisfaction, self-esteem), to enhance the perceived quality of working life (e.g., job satisfaction, organizational commitment), and to strengthen trust in their occupational future (e.g., entrepreneurial self-efficacy, occupational self-efficacy). In terms of our study, these findings are relevant in that these effects of BJW persisted when the authors controlled for objective parameters of occupational success, such as position in organizational hierarchy. In the present study, relationships between gender equality ratings and the measure of BJW were found to exist even at a time when widely publicized reports in Turkey were pointing to the professional environment as unjust toward women (UNDP, 2006, 2009).

The general belief in a just world, therefore, would appear to sustain well-being in the workplace and promote trust that others will act justly in an otherwise unjust environment, in accordance with the conceptualization of BJW as a self- 
protective, but somewhat illusory, cognitive mechanism. Providing an explanation of this phenomenon from another point of view, Alves and Correia (2008) found in their study that the expression of a higher degree of BJW is, in general, more socially valued than is the expression of a lower one. This would suggest that our results of high just world beliefs and the denial of systematic gender inequalities, reflect participants' attempts to endorse socially desirable values rather than their actual beliefs or even their own knowledge and experience of gender equality in the workplace. As Hafer and Bègue (2005) put it, lay people prefer acting as if the world were just, more than they actually know it to be just.

The moderation analyses that we conducted in Study 1 demonstrated that only people who believe the world is just link perceived gender equality to factors intrinsic to women. In other words, believing in overall justice would appear to sustain the contention that if women are not equal to men at work, this is because of their own choices. It is possible that, here again, BJW functions as a protective buffer variable for anger (cf. Dalbert, 2002) produced via the attributional process, by perception of low gender equality. Similar findings have been reported by Fetchenhauer, Jacobs, and Belschak (2005) who examined the role of belief in a just world and causal attributions of violence with a sample of victims of sexual aggression. They found that the greater the victims' personal belief in a just world, the better they were able to adjust to the experience of sexual violence. More importantly, their findings showed that the more victims used external attributions and the less they used internal attributions (one's own character and personality) the less distress the victims felt. The authors concluded that the relationship between adaptiveness and external attributions was moderated by just world beliefs. Following the same rationale, in the present study, when the relationship between equality perceptions and internal attributions is moderated by BJW, in cases where injustice is observed, internal attributions (the victim's own choices) serve to explain the injustice, and, thus, reduce feelings of distress.

From this perspective, Baumert and Schmitt (2009) recently discussed the role of justice sensitivity and suggested that people with greater justice sensitivity may experience greater injustice when restoration of justice is not possible. Causal attributions are one cognitive mechanism that offers the possibility to restore perceptions of injustice. In future studies it would be of value to include a measure of justice sensitivity in order to test specifically whether or not women globally differ from men in terms of justice sensitivity and, if they do, they, therefore, make more causal attributions.

In Study 2 the analyses first revealed that people who strongly believe the world is just, for both self and for others, perceive high gender equality and link low perceived gender equality to internal attributions, that is, to women's own choices. However, only believers in a just world for others linked their perceptions 
of gender equality to external attributions, such as social norms that discouraged or inhibited women from pursuing higher career paths. Our finding supports the links between measures of BJW-O and social discrimination indices, in terms of supporting social norms that endorse inequality between the genders in the workplace. Sutton et al. (2008) measured men's and women's justice beliefs and concluded that the high justice beliefs of both genders, in fact, reflected objective assessments of the justice received by men and women in their environment. In other words, men and women shared the belief that injustices suffered by women generally did not apply to women in the organization where the data were collected. Our results in the banking institution may be comparable. It is possible that the participants in the present study believed they had, and experienced, greater gender equality in their organization as compared to other organizations or to society in general.

In order to make the best response to the problem posed by the role of just world beliefs in social adjustment and social discrimination, the role of the individual victim of the discrimination is relevant. It would then be expected that just world belief for self would act to link internal attributions with low perceived equality for female, but not male, respondents, and that just world belief would act to link external attributions to low perceived equality for male, but not female, respondents. Boeckmann and Feather (2007), for instance, demonstrated in their study that women believe men are unfairly advantaged and that men believe women are responsible for their own disadvantage. These findings support the contention that attributional processes are activated only in the individual or group that is the target of inequality (Dalbert, 1998). However, our controls did not reveal any significant differences between male and female scores on any of the measured variables, and the moderation analyses did not reveal any significant gender effects on any of the tested interactions. Thus, we conclude that the moderating effect of belief in a just world in the relationships between perceptions of equality and attributions of low equality does not vary according to the function of the respondent being, or not being, a victim of gender inequality.

To the extent to which just world beliefs support the status quo, they both protect organizational well-being and hinder proactive attitudes toward change. Attitude change may come about more readily when public campaigns motivated by international bodies and promoting democratic governance point to direct ways of correcting gender inequality, whereby women are invited to take part more rather than conducting campaigns that evoke causal attributions to justify the status quo.

Our findings contribute to the large body of literature on the positive and negative effects of this attitudinal construct, pointing to the value of the self versus other distinction in elucidating the socially adverse correlates of the belief 
in a just world for others, such as the endorsement of social discriminations, and the sociopsychological benefits of the belief in a just world for the self, such as strengthened sense of well-being.

\section{References}

Aiken, L. S., \& West, S. G. (1991). Multiple regression: Testing and interpreting interactions. Newbury Park, CA: Sage.

Alves, H., \& Correia, I. (2008). On the normativity of expressing the belief in a just world: Empirical evidence. Social Justice Research, 21, 106-118. http://doi.org/ct7

Ararat, M., \& Tansel-Çetin, A. (2009). IMKB'de işlem gören bankaların kamuya açıklama yoğunluklarl ve yönetişim özellikleri [Public communication and management characteristics in banks performed in the Istanbul stock exchange]. Institutional Management Forum, Sabanci University, Istanbul: 7-8 November.

Baumert, A., \& Schmitt, M. (2009). Justice-sensitive interpretations of ambiguous situations. Australian Journal of Psychology, 61, 6-12. http://doi.org/ct8

Bègue, L. (2002). Beliefs in justice and faith in people: Just world, religiosity, and interpersonal trust. Personality \& Individual Differences, 32, 375-382. http://doi.org/d87vnz

Bègue, L., \& Bastounis, M. (2003). Two spheres of belief in justice: Extensive support for the bidimensional measure of belief in a just world. Journal of Personality, 71, 435-463. http://doi. org/cdm8wt

Boeckmann, R. J., \& Feather, N. T. (2007). Gender, discrimination beliefs, group-based guilt and responses to affirmative action for Australian women. Psychology of Women Quarterly, 31, 290-304. http://doi.org/ct9

Connors, J., \& Heaven, P. C. (1990). Belief in a just world and attitudes towards AIDS sufferers. The Journal of Social Psychology, 130, 559-560. http://doi.org/brjervd

Dalbert, C. (1998). Belief in a just world, well-being, and coping with an unjust fate. In L. Montada \& M. J. Lerner (Eds.), Responses to victimizations and belief in a just world (pp. 87-105). New York: Plenum.

Dalbert, C. (1999). The world is more just for me than generally: About the Personal Belief in a Just World Scale's validity. Social Justice Research, 12, 79-98. http://doi.org/cvc

Dalbert, C. (2002). Beliefs in a just world as a buffer against anger. Social Justice Research, 15, 123-145. http://doi.org/cvd

Dalbert, C., Fisch, U., \& Montada, L. (1992). Is inequality unjust? Evaluating women's career chances. European Review of Applied Psychology, 42, 11-18. http://doi.org/fvjc35

Dalbert, C., \& Yamauchi, L. A. (1994). Belief in a just world and attitudes toward immigrants and foreign workers: A cultural comparison between Hawaii and Germany. Journal of Applied Social Psychology, 24, 1612-1626. http://doi.org/dr9558

Dzuka, J., \& Dalbert, C. (2002). Mental health and personality of Slovak unemployed adolescents: The impact of belief in a just world. Journal of Applied Social Psychology, 32, 732-757. http:// doi.org/cvf

Fetchenhauer, D., Jacobs, G., \& Belschak, F. (2005). Belief in a just world, causal attributions, and adjustment to sexual violence. Social Justice Research, 18, 25-42. http://doi.org/cvg

Furnham, A. (1985). Just world beliefs in an unjust society: A cross cultural comparison. European Journal of Social Psychology, 15, 363-366. http://doi.org/cvh

Furnham, A. (2003). Belief in a just world: Research progress over the last decade. Personality and Individual Differences, 34, 795-817. http://doi.org/cvj

Furnham, A., \& Gunter, B. (1984). Just world beliefs and attitudes towards the poor. British Journal of Social Psychology, 23, 265-269. http://doi.org/cvk 
Furnham, A., \& Karani, R. (1985). A cross-cultural study of attitudes to women, just world, and locus of control beliefs. Psychologia: An International Journal of Research in the Orient, 28, 11-20.

Hafer, C. L., \& Bègue, L. (2005). Experimental research on just-world theory: Problems, developments, and future challenges. Psychological Bulletin, 131, 128-167. http://doi.org/cvm

Harper, D. J., \& Manasse, P. R. (1992). The just world and the Third World: British explanations for poverty abroad. The Journal of Social Psychology, 132, 783-785. http://doi.org/dbft9j

Harper, D. J., Wagstaff, G. F., Newton, J. T., \& Harrison, K. R. (1990). Lay causal perceptions of third world poverty and the just world theory. Social Behavior and Personality: An international journal, 18, 235-238. http://doi.org/cvp

Hofstede, G. (1980). Culture's consequences: International differences in work-related values. Newbury Park, CA: Sage.

Hofstede, G. (2001). Culture's consequences: Comparing values, behaviors, institutions and organizations across nations ( 2 nd ed.). Thousand Oaks, CA: Sage.

Jensen, E., Dehlin, B., Hagberg, B., Samuelsson, G., \& Svensson, T. (1998). Insomnia in an 80-year-old population: Relationship to medical, psychological and social factors. Journal of Sleep Factors, 7, 183-189. http://doi.org/cvq

Lerner, M. J. (1965). Evaluation of performance as a function of performer's reward and attractiveness. Journal of Personality and Social Psychology, 1, 355-360. http://doi.org/cvr

Lerner, M. J. (1980). The belief in a just world: A fundamental delusion. New York: Plenum.

Lerner, M. J., \& Miller, D. T. (1978). Just world research and the attribution process: Looking back and ahead. Psychological Bulletin, 85, 1030-1051. http://doi.org/dhv7gz

Lipkus, I. M., Dalbert, C., \& Siegler, I. C. (1996). The importance of distinguishing the belief in a just world for self versus for others: Implications for psychological well-being. Personality and Social Psychology Bulletin, 22, 666-677. http://doi.org/cvs

Lipkus, I. M., \& Siegler, I. C. (1993). The belief in a just world and perceptions of discrimination. The Journal of Psychology, 127, 465-474. http://doi.org/cvt

Littrell, J., \& Beck, E. (1999). Perceiving oppression: Relationships with resilience, self-esteem, depressive symptoms, and reliance on God in African-American homeless men. Journal of Sociology and Social Welfare, 26, 137-158.

Maes, J. (1998). Immanent justice and ultimate justice: Two ways of believing in justice. In L. Montada \& M. J. Lerner (Eds.), Responses to victimizations and belief in a just world: Critical issues in social justice (pp. 43-53). New York: Plenum.

Montada, L. (1998). Belief in a just world: A hybrid of justice motive and self-interest? In L. Montada \& M. J. Lerner (Eds.), Responses to victimizations and belief in a just world: Critical issues in social justice (pp. 217-246). New York: Plenum.

Otto, K., Glaser, D., \& Dalbert, C. (2009). Mental health, occupational trust, and quality of working life: Does belief in a just world matter? Journal of Applied Social Psychology, 39, 1288-1315. http://doi.org/cvv

Reichle, B., Schneider, A., \& Montada, L. (1998). How do observers of victimization preserve their belief in a just world cognitively or actionally? In L. Montada \& M. J. Lerner (Eds.), Responses to victimization and belief in a just world: Critical issues in social justice (pp. 55-86). New York: Plenum.

Ritter, C., Benson, D. E., \& Snyder, C. (1990). Belief in a just world and depression. Sociological Perspectives, 33, 235-252.

Ruggiero, K. M., \& Taylor, D. M. (1997). Why minority group members perceive or do not perceive the discrimination that confronts them: The role of self-esteem and perceived control. Journal of Personality and Social Psychology, 72, 373-389. http://doi.org/cvw

Smith, K. B. (1985). Seeing justice in poverty: The belief in a just world and ideas about inequalities. Sociological Spectrum, 5, 17-29. http://doi.org/d3frp4 
Sutton, R. M., \& Douglas, K. M. (2005). Justice for all, or just for me? More evidence of the importance of the self-other distinction in just-world beliefs. Personality and Individual Differences, 39, 637-645. http://doi.org/cvx

Sutton, R. M., Douglas, K. M., Wilkin, K., Elder, T. J., Cole J. M., \& Stathi, S. (2008). Justice for whom, exactly? Beliefs in justice for the self and various others. Personality and Social Psychology Bulletin, 34, 528-541. http://doi.org/cvz

Tomaka, J., \& Blascovich, J. (1994). Effects of justice beliefs on cognitive appraisal of and subjective, physiological, and behavioral responses to potential stress. Journal of Personality and Social Psychology, 67, 732-740. http://doi.org/cv2

Turkish Bank Association. (2009). The financial system and banking sector in Turkey. Accessed at http://www.tbb.org.tr/english/duyurular/The_Financial_System_and_Banking_Sector_in_ Turkey.pdf

United Nations Development Programme. (2006). Country Programme Document, 2006-2010. Accessed at http://www.undp.org.tr/demGovDocs/Enhancing_Womens_Participation_ Signed_Project_Document.pdf

United Nations Development Programme. (2009). Human Development Report 2009. Accessed at http://www.undp.org.tr/publicationsDocuments/Table_K_from_HDR_2009_EN_Gender_ Empowerment_Measure.pdf

Wagstaff, G. F. (1983). Correlates of the just world in Britain. The Journal of Social Psychology, 121, 145-146. http://doi.org/c2jhs7

Wagstaff, G. F., \& Quirk, M. A. (1983). Attitudes to sex-roles, political conservatism and belief in the just world. Psychological Reports, 52, 813-814. http://doi.org/dz8nsp

Zuckerman, M. (1975). Belief in a just world and altruistic behavior. Journal of Personality and Social Psychology, 31, 972-976. http://doi.org/cv3 